\title{
A Case Report of Empty Sella Syndrome secondary to Hantaan Virus Infection and Review of the Literature
}

Lixin Lou

Jilin University

Peng Zhang

Jilin University

Bin Wang

Jilin University

Yang Wang ( $\nabla$ wyang@jlu.edu.cn )

Jilin University https://orcid.org/0000-0001-8055-9522

\section{Case report}

Keywords: Empty sella syndrome; hemorrhagic fever with renal syndrome; imaging examination

Posted Date: April 24th, 2019

DOI: https://doi.org/10.21203/rs.2.9316/v1

License: (c) (i) This work is licensed under a Creative Commons Attribution 4.0 International License. Read Full License 


\section{Abstract}

Background Bleeding in the anterior pituitary lobe leading to tissue necrosis occurs in acute stage of severe clinical forms of hemorrhagic fever with renal syndrome (HFRS), while atrophy of the anterior pituitary lobe with diminution of the gland function occurs after recovery stage. The relationship between hantaan virus infection and empty sella syndrome (EES) was reported rarely. Case presentation We herein report a case of EES secondary to hantaan virus infection. This patient was a 54-year-old previously healthy Chinese male. He presented with fever, headache and backache with dizziness and oliguria. Physical examination was notable for hypotention and the signs of conjunctival suffusion. His platelet dropped and the urine protein was positive. The IgM to Hantaan virus and virus RNA were positive. Then he was diagnosed as hemorrhagic fever with renal syndrome. But in his diuretic phase, his 24-hour urine volume was still kept on the level of $10,000 \mathrm{ml}$ and his blood pressure was obviously higher for a week. Then the examination of pituitary function and brain magnetic resonance imaging were performed. The levels of the hormones were much lower and the magnetic resonance imaging results indicated empty sella. The patient's symptoms were improved and he was discharged from the hospital soon after hormone replacement therapy. Conclusions The examination of pituitary function and MRI of brain need to be considered to scan ESS and panhypopituitarism in the patients with HFRS accompanied with diabetes insipidus.

\section{Background}

The term "empty sella" was first used in 1951 for the neuroradiological or pathological-anatomical exposure of an apparently empty sella turcica. Empty sella syndrome (ESS) is pathophysiologically characterized by either anatomic abnormalities in the diaphragma sellae (primary ESS) or damage to the pituitary by irradiation/surgery, or autoimmunity leading to the availability of "empty" space in the sella (secondary ESS) [1]. The most prevalent hormone deficiency in this syndrome is growth hormone (GH) deficiency, affecting 35 to $61 \%$ of adult patients with ESS [2]. The most common symptom of empty sella syndrome include headache. Generally the headache is deep, dull and centrally situated. Sometimes headache is very severe along with giddiness and vomiting that before imaging examination [1].

In primary ESS, the sella tends to be symmetrically ballooned without evidence of bony lesion. The suprasellar sub-arachnoid space herniates through an incomplete diaphragm-sella. Cisternography, high resolution computed tomography (CT) scanning or magnetic resonance imaging (MRI). The signs and symptoms depend upon the size, secretion and pressure over the pituitary gland. Before the era of CT Scan many cases of empty sella were wrongly diagnosed [3]. Empty sella is the neuroradiological or pathological finding of an apparently empty sella turcica containing no pituitary tissue. The prevalence of primary empty sella, i.e., empty sella without any discernible cause, is not precisely known; estimates range from $2 \%$ to $20 \%$ [3]. Technical advances in neuroradiology have made empty sella an increasingly incidental finding. We can assume that improvements in neuroradiological imaging techniques have resulted in an increase in the incidental finding of an "empty sella". According to current data from India, an empty sella turcica without any detectable cause is an incidental finding in about $2 \%$ of all cerebral 
MRI scans [4]. In asymptomatic adult patients, the question is whether and to what extent diagnostic hormone testing should be undertaken in an incidental finding of an empty sella, particularly as this does not necessarily have pathological significance.

The causes of most of the primary EES are still not clear. Hemorrhagic fever with renal syndrome (HFRS) is acute infective multisystemic disease followed by febrility, hemorrhages and acute renal insufficiency. Bleeding in the anterior pituitary lobe leading to tissue necrosis occurs in acute stage of severe clinical forms of HFRS, while atrophy of the anterior pituitary lobe with diminution of the gland function occurs after recovery stage. The relationship between hantaan virus infection and EES was reported rarely.

Herein, we present an adult case with ESS induced by HFRS. He was cured after support treatment and hormone replacement therapy.

\section{Case Presentation}

This patient was a 54-year-old previously healthy Chinese male with no significant past medical history and surgical history. He lived in a rural area with high incidence of HFRS. He presented with fever, headache and backache for 5 days in winter. It was the epidemic season of HFRS. He suddenly experienced fever up to $40^{\circ} \mathrm{C}$. He felt ocular pain sometimes without visual disturbance. He felt dizzy, but he did not take his blood pressure examined. He found oliguria during the last 3 days, but his urine output was not clear. Vomiting and abdominal pain were also been experienced.

Physical examination was notable for a blood pressure of $88 / 53 \mathrm{mmHg}$, weight $=62 \mathrm{~kg}$, height $=5^{\prime} 7^{\prime \prime}$, and body mass index $=21.5$. His body temperature recovered to the normal level as $37^{\circ} \mathrm{C}$. The signs of conjunctival suffusion (flush over face, flush over neck and upper chest) were found.

Laboratory tests results were as follows: The blood routine examination: WBC (55, 000 cells $/ \mathrm{mL})$, percentage of neutrophils $(61.9 \%)$ and platelet $(93,000 \mathrm{cells} / \mathrm{mL})$. The urine examination: Protein (strong positive). Liver enzymes were increased (aspartate aminotransferase $57.3 \mathrm{U} / \mathrm{L}$, alanine aminotransferase $61.0 \mathrm{U} / \mathrm{L}$, gamma glutamyl transferase $102.0 \mathrm{U} / \mathrm{L}$ ). Renal function was abnormal (Creatinine $138 \mu \mathrm{mol} / \mathrm{L}$, blood urea nitrogen $7.8 \mathrm{mmol} / \mathrm{L}$ ). The RT-PCR test result of Hantaan virus is positive. The result of antibody IgM to Hantaan virus was positive, while antibody IgG to Hantaan virus was negative. But the result of antibody IgG to Hantaan virus was positive a week later and the titer of antibody IgG increased 4 times compared with that of the first test. The C-reactive protein (CRP) level was $105 \mathrm{mg} / \mathrm{L}(0-3.5)$ and the serum procalcitonin (PCT) was $1.3 \mu \mathrm{g} / \mathrm{L}(0.05-0.5)$.

The urine output during the first 24-hour admission in our department was less than $200 \mathrm{ml}$. He was diagnosed as overlap with hypotensive phase and oliguric phase of HFRS. After supportive measures treatment, the patient develop into polyuric phase within a week. The result of regular blood cell test was normal. His urine volume was significantly higher than normal and the 24-hour urine volume was still kept on the level of 10,000 $\mathrm{ml}$ and his blood pressure was obviously higher than his usual level for a week. He felt fatigue obviously. Then the examination of pituitary function was performed. All the results 
were much lower than the reference range (the urinary free cortisol: $3.95 \mathrm{nmol} / 24 \mathrm{~h}$ (108-961); thyroid stimulating hormone: $0.075 \mathrm{ulU} / \mathrm{ml}$ (0.27-4.2), free T3 $1.78 \mathrm{pmol} / \mathrm{L}$ (3.1-6.8), free T4 $8.2 \mathrm{pmol} / \mathrm{L}$ (12-22); 0:00 Serum cortisol: <11 nmol/I (240-619), 8:00 Serum cortisol: <11 nmol/l (240-619), 16:00 Serum cortisol: <11 nmol/l (240-619); 0:00 plasma adrenocorticotropic hormone: 0.22 pmol/L (1.6-13.9), 8:00 plasma adrenocorticotropic hormone: $0.22 \mathrm{pmol} / \mathrm{L}$ (1.6-13.9), 16:00 plasma adrenocorticotropic hormone: $0.22 \mathrm{pmol} / \mathrm{L}$ (1.6-13.9); Prolactinemia: $11.00 \mathrm{mIU} / \mathrm{L}$ (55.97-278.36); Follicle-stimulating hormone: $0.470 \mathrm{mlU} / \mathrm{mL}$ (1.27-19.26); growth hormone: $0.026 \mathrm{ng} / \mathrm{ml}$ (0.003-0.971); luteinizing hormone: $0.420 \mathrm{mIU} / \mathrm{mL}$ (1.24-8.62); serum testosterone: $<0.35 \mathrm{nmol} / \mathrm{L}(6.07-27.1))$. The result of brain MRI showed that signal of cerebrospinal fluid could be observed in sella (Fig. 1).

The patient's symptoms were improved and he was discharged from the hospital soon after hormone replacement therapy. His urine amount and the results of pituitary function tests recovered to the normal range and the only discomfort-fatigue disappeared one month later.

\section{Discussion And Conclusions}

HFRS is a zoonotic disease caused by pathogenic hantaviruses. China is the most seriously affected country with more than 10,000 cases reported annually and accounts for over $90 \%$ of all cases over the world [5, 6]. During 1950-2014, the death rate of HFRS was reported as $2.89 \%$, according to the statistical data from the national health and Family Planning Commission of China [7].

CRP, secreted by the liver in response to bacterial infections, is a parameter used to diagnose infection. $\mathrm{PCT}$, a precursor of calcitonin, is a diagnostic marker of systemic inflammatory response, with a high sensitivity and specificity for infection. PCT and CRP have been used as new approaches to identify different types of infection [8]. It is known that serum PCT levels are higher in bacterial, fungal, and parasitic infections than in viral infections or non-infected patients, which has made PCT a guide to antibiotic treatment in pneumonia. PCT levels could be useful in discriminating between these conditions, could help physicians' decisions on using antibiotics or not. HFRS is caused by virus infection. In the epidemic area, the cases with typical symptoms and laboratory findings could be diagnosed by experienced professional doctors soon. But in some cases, it need to be differentiated diagnosis with severe bacteria infection, such as septicemia.Doctors were used to making a quick judgment according the lever of CRP and PCT before the result of blood culture returns. But the inflammatory biomarkers increased obviously in this case. It was reported that elevated levels of CRP and PCT were present in more than $90 \%$ of patients with HFRS [9]. The elevated level of PCT in HFRS may be related with and immune activation caused by hantavirus [10]. As well as elevated C-reactive protein levels were shown to in patients with hantavirus infection. But whether the elevation of CRP and PCT were associated with the severity of HFRS is still a controversial issue [10-12].

It is well accepted that the main clinical hallmarks of HFRS are renal failure and hemorrhagic manifestations, and that the disease is characterized by laboratory findings indicating renal function impairment, thrombocytopenia, and elevated ALT levels [9]. Vascular endothelial dysfunction is the basic 
pathological change and hemorrhage in vital organ could lead to death. But acute impaired pituitary function was not reported in HFRS patients. The main treatment for HFRS is supportive measures. The effect of antiviral drugs (e.g. ribavirin) remains controversial and is still still a hot topic of research $[7,13]$. Maintaining fluid and electrolyte balance is a crucial and fundamental treatment method to the patients with HFRS. Especially in the polyuric phase, most doctor believe that other additional treatment and tests are not necessary except the supportive treatment and blood and urine regular retests. In general, the polyuric phase last for about 1 - 2 weeks. In this case, the patient's 24-hour urine volume was kept on the level of $10,000 \mathrm{ml}$ and his blood pressure was obviously higher than his usual level for a week. After pituitary function and MRI of brain were detected, impaired pituitary function and empty sella were found. The patient's symptoms, such as polyuria, hypertention and fatigue, were relieved soon after hormone replacement therapy. Secondary empty sella may be caused by pituitary adenomas undergoing spontaneous necrosis (ischemia or hemorrhage). Numerous studies have shown that empty sella syndrome may be associated with pituitary dysfunction contrary to the notion of it being an incidental finding [14]. Pituitary hemorrhage and necrosis was found in cases of death with HFRS via autopsy studies, but the incidence rate of pituitary necrosis is very low. It was reported a case with hemorrhagic fever with renal syndrome accompanied by panhypopituitarism and central diabetes insipidus recently [15]. But the pituitary MRI findings were normal in that case. The ESS was reported as a late complication of HFRS in 4 cases, among whom ESS was found six years after he was diagnosed as HFRS $[16,17]$. Howerver, our case was diagnosed as ESS in his hospital admission during the polyuric phase of HFRS. The pathogenesis of the pituitary injury induced by hantaan virus infection need to be convinced by further research.

It was recommended that overdiagnosis of empty sella should be avoided as this might upset patients unnecessarily, and it also incurs substantial expense to the healthcare system [18]. On the other hand, treating hormonal dysregulation has a positive effect on morbidity and quality of life [19]. In the polyuric phase of HFRS, the patients need to be monitored carefully. The examination of pituitary function and MRI of brain need to be considered to scan ESS and panhypopituitarism in the patients with HFRS accompanied with diabetes insipidus. Appropriate hormone replacement therapy could help the patients to relieve soon.

\section{Abbreviations}

ESS: Empty sella syndrome GH: Growth hormone CT: Computed tomography MRI: Magnetic resonance imaging HFRS: Hemorrhagic fever with renal syndrome RT-PCR: Real-time polymerase chain reaction CRP: C-reactive protein PCT: procalcitonin

\section{Declarations}

\section{Ethics approval and consent to participate}

Not applicable. 


\section{Consent for publication}

We obtained the written consent from the patient for the publication of the medical data. Patient privacy was fully protected and personal information was handled such that the patient could not be identified.

\section{Availability of data and material}

Date sharing is not applicable to this article as no datasets were generated or analyzed during the current study.

\section{Competing interests}

The authors declare that they have no competing interests.

\section{Funding}

This work is supported by National Natural Science Foundation of China, No. 81801972. The funders had no role in the collection or interpretation of data.

\section{Authors' contributions}

$\mathrm{LL}$ analyzed and interpreted the patient data. PZ and BW diagnosis and treatment of the patient. YW reviewed and edited the manuscript. All the authors read and approved the manuscript.

\section{Acknowledgements}

Thanks for efforts of radiological technicians and neurosurgeons in clinical diagnosis and management of this patient.

\section{References}

[1] Sethuraman VK, Viswanathan S, Aghoram R. Refractory Hypoglycemia and Seizures as the Initial Presenting Manifestation of Empty Sella Syndrome. Cureus. 2018; 10(6):e2803. doi:

10.7759/cureus.2803. 
[2] Arzamendi AE, Shahlaie K, Latchaw RE, Lechpammer M, Arzumanyan H. Ectopic Acromegaly Arising from a Pituitary Adenoma within the Bony Intersphenoid Septum of a Patient with Empty Sella Syndrome. J Neurol Surg Rep. 2016; 77(3):e113-7. doi: 10.1055/s-0036-1585091.

[3] Auer MK, Stieg MR, Crispin A, Sievers C, Stalla GK, Kopczak A. Primary Empty Sella Syndrome and the Prevalence of Hormonal Dysregulation. Dtsch Arztebl Int. 2018; 115(7):99-105. doi:

10.3238/arztebl.2018.0099.

[4] Debnath J, Ravikumar R, Sharma V, Senger KP, Maurya V, Singh G, et al. 'Empty sella' on routine MRI studies: an incidental finding or otherwise? Med J Armed Forces India. 2016; 72:33-37. doi:

10.1016/j.mjafi.2015.11.012.

[5] Fan X, Liu Z, Fu S, Sang J, Deng H, Li F, et al. Platelet Distribution Width at First Day of Hospital Admission in Patients with Hemorrhagic Fever with Renal Syndrome Caused by Hantaan Virus May Predict Disease Severity and Critical Patients' Survival. Dis Markers. 2018; 2018:9701619. doi: $10.1155 / 2018 / 9701619$.

[6] Wu H, Wang X, Xue M, Wu C, Lu Q, Ding Z, et al. Spatial-temporal characteristics and the epidemiology of haemorrhagic fever with renal syndrome from 2007 to 2016 in Zhejiang Province, China. Sci Rep. 2018; 8(1):10244. doi: 10.1038/s41598-018-28610-8.

[7] Jiang H, Du H, Wang LM, Wang PZ, Bai XF. Hemorrhagic Fever with Renal Syndrome: Pathogenesis and Clinical Picture. Front Cell Infect Microbiol. 2016; 6:1. doi: 10.3389/fcimb.2016.00001.

[8] Tang JH, Gao DP, Zou PF. Comparison of serum PCT and CRP levels in patients infected by different pathogenic microorganisms: a systematic review and meta-analysis. Braz J Med Biol Res. 2018; 51(7):e6783. doi: 10.1590/1414-431x20176783.

[9] Pal E, Korva M, Resman Rus K, Kejžar N, Bogovič P, Kurent A, et al. Sequential assessment of clinical and laboratory parameters in patients with hemorrhagic fever with renal syndrome. PLoS One. 2018; 13(5):e0197661. doi: 10.1371/journal.pone.0197661.

[10] Yu Z, Zhou N, Li A, Chen J, Chen H, He Z, et al. Performance assessment of the SAPS II and SOFA scoring systems in Hanta virus Hemorrhagic Fever with Renal Syndrome. Int J Infect Dis. 2017; 63:88-94. doi: 10.1016/j.ijid.2017.08.003.

[11] Fan X, Deng H, Sang J, Li N, Zhang X, Han Q, et al. High Serum Procalcitonin Concentrations in Patients With Hemorrhagic Fever With Renal Syndrome Caused by Hantaan Virus. Front Cell Infect Microbiol. 2018; 8:129. doi: 10.3389/fcimb.2018.00129.

[12] Latus J, Schwab M, Tacconelli E, Pieper FM, Wegener D, Dippon J, et al. Clinical course and long-term outcome of hantavirus-associated nephropathia epidemica, Germany. Emerg Infect Dis. 2015; 21(1):7683. doi: $10.3201 /$ eid2101.140861. 
[13] Moreli ML, Marques-Silva AC, Pimentel VA, da Costa VG. Effectiveness of the ribavirin in treatment of hantavirus infections in the Americas and Eurasia: a meta-analysis. Virusdisease. 2014; 25(3):385-9. doi: 10.1007/s13337-014-0219-7.

[14] De Marinis L, Bonadonna S, Bianchi A, Maira G, Giustina A. Primary empty sella. J Clin Endocrinol Metab. 2005; 90(9):5471-7.

[15] Ahn HJ, Chung JH, Kim DM, Yoon NR, Kim CM. Hemorrhagic fever with renal syndrome accompanied by panhypopituitarism and central diabetes insipidus: a case report. J Neurovirol. 2018; 24(3):382-387. doi: 10.1007/s13365-018-0624-6.

[16] Pekic S, Cvijovic G, Stojanovic M, Kendereski A, Micic D, Popovic V. Hypopituitarism as a late complication of hemorrhagic fever. Endocrine. 2005; 26(2):79-82.

[17] Stojanovic M, Pekic S, Cvijovic G, Miljic D, Doknic M, Nikolic-Djurovic M, et al. High risk of hypopituitarism in patients who recovered from hemorrhagic fever with renal syndrome. J Clin Endocrinol Metab. 2008; 93(7):2722-8. doi: 10.1210/jc.2008-0311.

[18] Brownlee S, Chalkidou K, Doust J, Elshaug AG, Glasziou P, Heath I, et al. Evidence for overuse of medical services around the world. Lancet. 2017;390:156-168. doi: 10.1016/S0140-6736(16)32585-5.

[19] Webb SM, Crespo I, Santos A, Resmini E, Aulinas A, Valassi E. Management of endocrine disease: quality of life tools for the management of pituitary disease. Eur J Endocrinol. 2017; 177:R13-R26. doi: 10.1530/EJE-17-0041.

\section{Figures}

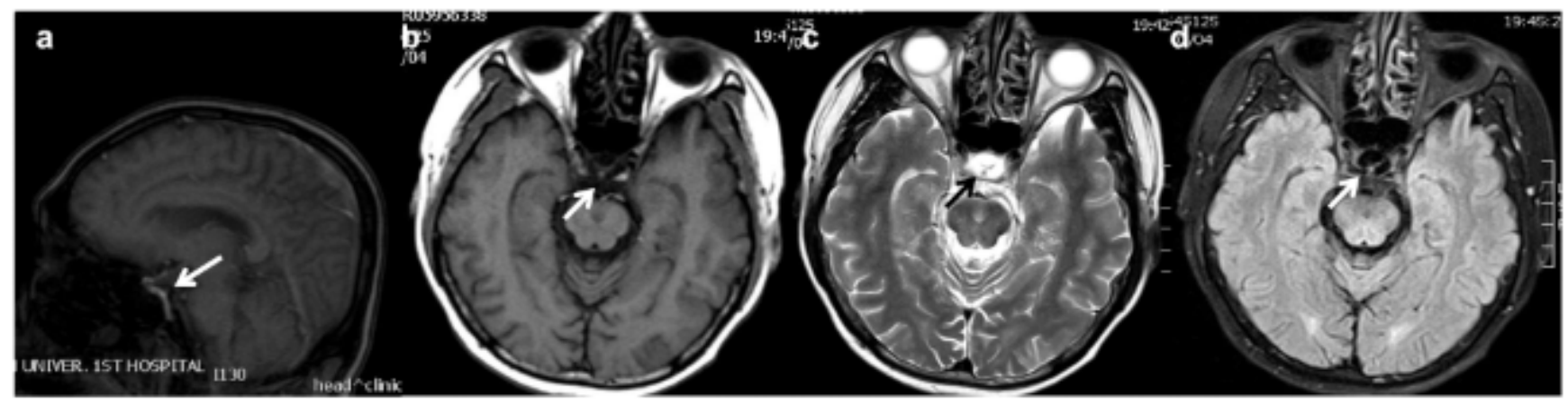

\section{Figure 1}

The MRI scan of the brain. a Sagittal T1-weighted image to show a empty sella partially filled with cerebrospinal fluid (CSF) (white arrow). b T1-weighted image taken in the coronal plane showing hypointesity over the sella region (white arrow). c T2-weighted image taken in the coronal plane showing 
hyperintensity with "black target sign" over the sella region (black arrow). $d$ T2-tirm dark fluid image taken in the coronal plan showing hypointesity over the sella region and indicating filled with CSF (white arrow).

\section{Supplementary Files}

This is a list of supplementary files associated with this preprint. Click to download.

- CAREchecklistEnglish2013.pdf 